\title{
Research on Stress Characteristics of Planetary Gear Drive with Small Tooth Number Difference
}

\author{
Xiaoning Feng \\ Mechanical \& Electrical Engineering College, Jiaxing University, Jiaxing, 314001, China \\ email: fengxnsx@126.com
}

\begin{abstract}
Keywords: mechanics; planetary gear drive with small tooth number difference; multi-teeth meshing effect; bending strength; finite element method
\end{abstract}

\begin{abstract}
In order to study on the multi-teeth meshing phenomenon of involute internal gear pairs with small tooth number difference, precise entity assembly models of internal gear pairs are established, finite clement analyses for the multi-teeth contact problem are carried out, characteristics of the tensile stress and the contact stress are revealed, a sharp angle effect of the multi-teeth meshing is discovered and the maximum number of the meshing teeth pairs is provided.
\end{abstract}

\section{Introduction}

The thesis creates an accurate entity assembly model for involute internal gear pairs with small tooth number difference by adopting the GearTeq and SolidWorks, carries out finite element computing through SolidWorks Simulation and discovers the multi-teeth meshing phenomenon and characteristics.

The involute internal gear pairs with small tooth number difference often uses stub gear and the common tooth number difference is within five. Due to limited space, the thesis will only deal with stub gear of the addendum coefficient $h_{a}^{*}=0.8$ and further explain the calculation condition of the one-tooth difference and the five-tooth difference.

\section{Accurate modeling method for the entity assembly model of internal gear pairs}

GearTeq is an excellent tool for creating gear drive model, which can create many kinds of gear parts model or assembly model and boasts of high level of tooth profile precision and meshing precision. The gear model created by this software is the drive model of gear model. The three-dimensional entity model of gear can only be created through SolidWorks.

Method for establishing the entity assembly model for internal gear pairs. Open "Insert New Component" menu of the GearTeq, choose "New Planetary Set...", open dialog box of "Add Planet", choose "Cycloid Gear Sets", click "Accept" and then the basic model for involute internal gear pairs with small tooth number difference can be created. Then modify the gear parameter as required, and GearTeq will generate an entity assembly drive model matching the relevant parameters.

Open SolidWorks, choose the option of "Create CAD Models and Assembly" from the "CAD" menu of GearTeq, open the dialog box, click "Create component models and assembly" button, and then click the "Create in Soliworks" button, the entity assembly model can be created in SolidWorks.

Setting of the meshing position of internal gear pairs. The internal gear pairs generated through the above-mentioned method often don't locate in the necessary meshing position, so the meshing position of the internal and external gear can be adjusted by using the "Mates" toolbar of the "Assembly" model.

Choose the "Gear Mates" option of the "Mechanical Mates", input the pitch diameters of the internal and external gear, and guarantee the meshing relation of internal and external gear.

Make sure the same side surface of the two gears coincide through the "Coincident Mate" option.

Make sure the center distance of the two gears is fixed through the "Distance" option. 
Adjust the "Fix" setting of the internal gear to "Float".Make sure the inner circle surface of the external gear and the outside circle surface of the internal gear are concentric with their axis respectively through the "Concentric" option.Note: the setting cannot be carried out by using the mark of the gear axis "+"; enter the "Sketch" model, choose the side face of the external gear as the sketching plane, draw a "Point" at the gear axis, and then set the "Concentric" by taking the two "Point" as the axis, so is the internal gear.

After entering the "Sketch" model, draw the line of action of the internal gear pairs. It can be adjusted to the meshing position required, for example, the addendum meshing position, according to the line of action of the drive gear.

\section{Calculation parameters of involute internal gear pairs with small tooth number difference}

This paper completed twenty models of finite element analysis for involute internal gear pairs with small tooth number difference,ten models of one-tooth difference and ten models of one-tooth difference,the basic parameters are: addendum coefficient $h_{a}^{*}=0.8$, module $m=1 \mathrm{~mm}$, face width $b=1 \mathrm{~mm}$, The tooth number of the external gear $z_{1}=30,40,50,60,70,80,90,100,150,200$ and the tooth number of the internal gear $z_{2}$ is determined by the tooth number $z_{2}-z_{1}$, the one-tooth difference $z_{2}=z_{1}+1$, and the five-tooth difference $z_{2}=z_{1}+5$. The shift coefficient of the external gear $x_{1}$ is set as 0 , the shift coefficient of the internal gear are respectively $x_{2}=0.6$ (one-tooth difference ) and $x_{2}=0.16$ (the five-tooth difference) so as to make sure that the contact ratio $\sigma_{F 1}$ is greater than 1 and the value of the profile overlap interference $G_{\mathrm{s}}$ can be within 0.2 and 0.3 . The root fillet radius are respectively $\rho_{1}=0.3 \mathrm{~m}$ (the external gears)and $\rho_{2}=0.15 \mathrm{~m}$ (the internal gear).

The tangential force of the external gear is $F_{t}=100 \mathrm{~N} / \mathrm{mm}$ and then inverse calculate the torque $T, T$ equals to $100 \mathrm{~N}$ multiplied by reference circle radius.

\section{Method to create the finite element model of involute internal gear pairs with small tooth number difference}

Create a "static" Analysis using the SolidWorks Simulation and finish the modeling work based on contact problem.

Setting of material properties.The material of the two gears is alloy steel with the elastic modulus $E=2.1 \times 10^{5} \mathrm{MPa}$, Poissons ratio $\mu=0.28$ and yield strength $\sigma_{s}=620.42 \mathrm{MPa}$.

Constraints and load of the gear model.The outside circle of the internal gear is set as "Fixed Geometry" constraint and the inner bore of the external gear is set as "Fixed hinge" so that the external gear can only rotate around its axial line. The torque $T$ can apply the force on the inner bore of the external gear clockwise.

Setting of the contact set.A multi-body contact model shall be created to analyse the multi-teeth meshing phenomenon of involute internal gear pairs with tooth number difference. As the software cannot judge the number of the meshing gear teeth automatically, the contact set need to be selected manually. The tooth surface of the external gear is set as the original contact surface and that of the internal gear is set as the target contact surface. The accuracy of the calculation can be guaranteed when the number of the contact set is greater than the actual meshing teeth pairs. More contact sets shall be set when the teeth number increases.

For example, when $z_{1}=100, z_{2}=100$, there are 9 contact set (see Figure 1). For the convenience of explanation, virtual number is added. The tooth pair 4-4'and 5-5' are theoretical meshing tooth pair, tooth pair $5-5^{\prime}$ is arranged in the middle and tooth 5 of the external gear is set as the tip of the tooth contact. The contact surface is "no penetration", the friction coefficient is 0.05 . 


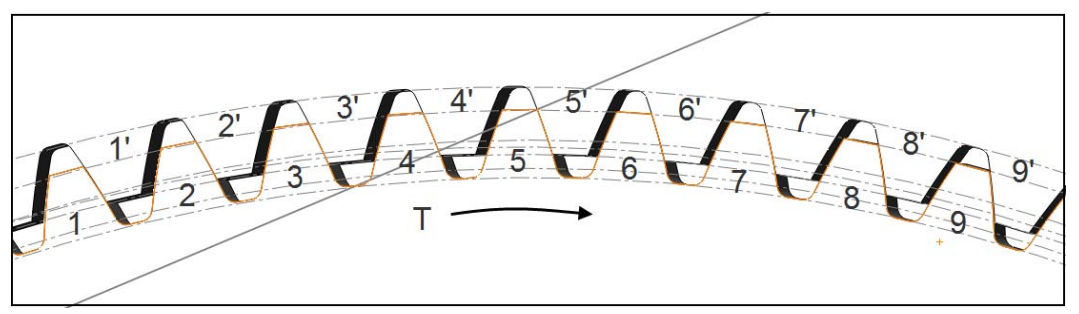

Figure 1 Setting condition of the contact set

Mesh division of gear model. The division of mesh has a great impact over the accuracy of finite element analysis, calculation amount and length of time. First refine the gear mesh of the contact set by adopting the option of " mesh control"and then create the mesh through the option of "generating mesh". Make sure the mesh of the tooth body is spare and that of partial gear tooth is fine. When $z_{1}=100, z_{2}=100$, the mesh division can be seen in Figure 2. The calculation indicates that with the reduction of the mesh control size at the refined place, the root tensile stress possesses the property of astringency, which is set as $0.2 \mathrm{~mm}$.

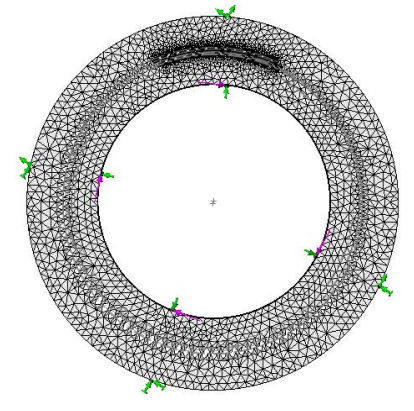

(a) Overall mesh division

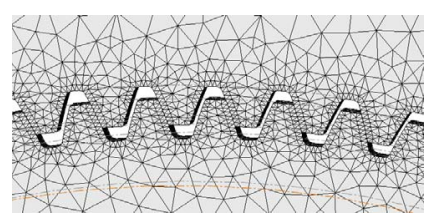

(b) Partial mesh division

Figure 2 The mesh division of the internal gear pairs

\section{Finite element analysis of involute internal gear pairs with small tooth number difference}

First, analyze two cases of one-tooth difference (Case 1: $z_{1}=30$ and $z_{2}=31$; Case 2: $z_{1}=100$ 、 $z_{2}=101$ ), and then analyze two cases of five-tooth difference (Case 3: $z_{1}=30$ and $z_{2}=35$; Case 4: $\left.z_{1}=100 、 z_{2}=105\right)$.

Analysis of the root tensile stress.In order to carry out a simulation analysis of the multi-teeth phenomenon, it can be calculated by adopting the method of gradually increasing the setting number of the contact set. The calculation data of the root tensile stress in case 1 and case 2 can be seen in table 1 and table 2 (The data showed is only related to the root tensile stress of the external gear $\sigma_{F 1}$ when the number of the contact set is an odd number).

Table 1 Calculation data of the root tensile stress of the external gear in case $1[\mathrm{MPa}]$

\begin{tabular}{cccccc}
\hline \multirow{2}{*}{$\begin{array}{c}\text { Number of contact } \\
\text { set }\end{array}$} & 1 & 2 & 3 & 4 & 5 \\
\hline 1 & & & 335 & & \\
3 & & 121 & 179 & $(34)$ & $(23)$ \\
5 & $(5)$ & 117 & 179 & $(33)$ & \\
\hline
\end{tabular}


Table 2 Calculation data of the root tensile stress of the external gear in case 2 [MPa]

\begin{tabular}{cccccccccc}
\hline \multirow{2}{*}{ Number of contact set } & \multicolumn{10}{c}{ Contact set No. } \\
\cline { 2 - 9 } & 1 & 2 & 3 & 4 & 5 & 6 & 7 & 8 & 9 \\
\hline 1 & & & & 88 & 91 & 111 & & & \\
3 & & 53 & 53 & 57 & 67 & 54 & & \\
5 & 18 & 47 & 47 & 51 & 59 & 52 & $(22)$ & \\
7 & 0 & 16 & 47 & 47 & 51 & 59 & 52 & $(21)$ & $(13)$ \\
9 & & &
\end{tabular}

It can be inferred from the above data that the number if the meshing teeth increases with the increasing of the number of the contact set, the root tensile stress decreases, but both shows the property of astringency. For instance, when the number of the contact set is set as 5 pairs in case 1 and 9 pairs in case 2, the root tensile stress reaches a fixed value,the meshing teeth in case 1 reaches 2 pairs, which is the theoretical meshing teeth pairs; the meshing teeth in case 2 reaches 6 pairs, non-theoretical meshing teeth occurs. The reason for that phenomenon can be explained as below: as the number of the teeth increases, the clearance of both sides teeth of the theoretical meshing teeth pairs are decreased and the deformation caused by load can eliminate the clearance thus cause the non-theoretical meshing teeth to participate the meshing. Nephogram of the root tensile can be seen in Fugure 3.

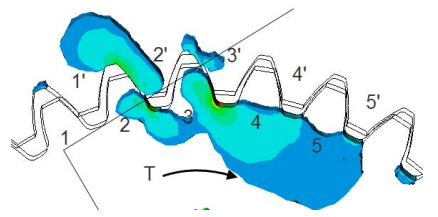

(a) Case 1

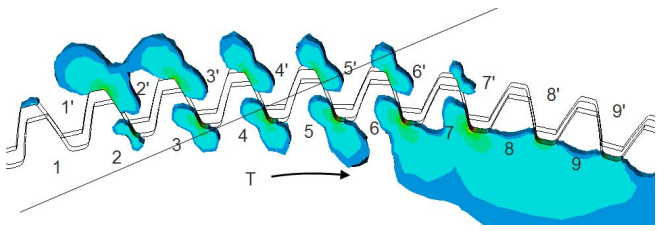

(b) Case 2

Fugure 3 Nephogram of the root tensile stress

The stress bracketed in Table 1 and Table 2 isn't the tensile stress generated by teeth contact but that jointly produced by the deformation of the gear ring and the root fillets stress. For instance, the root tensile stress of tooth 4 and tooth 5 in case 1, tooth 8 and tooth 9 in case 2 (see Figure 3 ).

Maximum value of the root tensile stress. When one pair of teeth meshes, the maximum value of the root tensile stress lies on the addendum-meshed tooth that is arranged in the middle. When several pairs of teeth mesh, the maximum value of the root tensile stress of the external gear transfers to the meshing-out teeth and the internal gear transfers to the meshing-in teeth. In case 2, for instance, when one pair of teeth meshes, the maximum value of the root tensile stress of the external gear lines on tooth 5, and when several pairs of teeth meshes, it transfers to tooth 7.

Analysis of tooth surface contact stress. When the number of the contact set in case 1 is set as 5 pairs and 9 pairs in case 2 , the vector diagram of the contact stress $\sigma_{\mathrm{H}}$ can be seen in Figure 4 , the distribution diagram can be seen in Figure 5. It can be clearly found that the meshing gear teeth in case 1 reach 2 pairs and 6 pairs in case 2 .

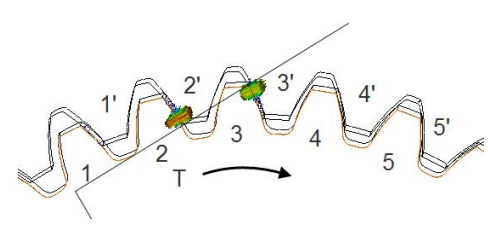

(a) Case 1

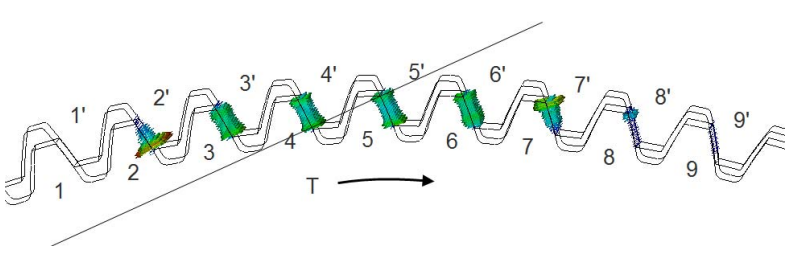

(b) Case 2

Figure 4 Vector diagram of contact stress 


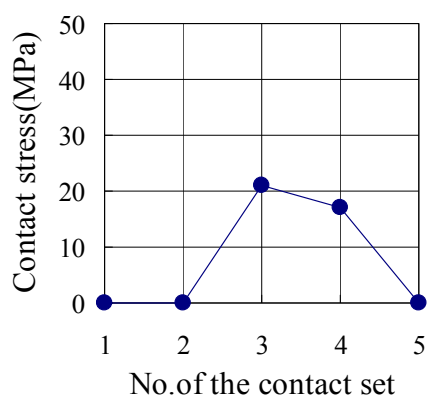

(a) Case 1

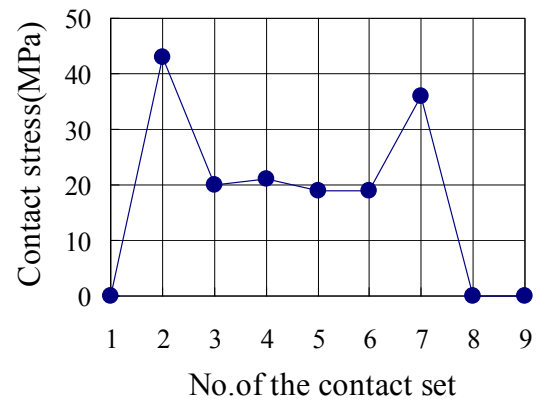

(b) Case 2

Figure 5 Distribution diagram of contact stress

Acute angle effect.The number of the meshing teeth pair will increase with the increasing of the tooth number, the distribution of contact stress will transform from convex profile to concave profile, namely the contact stress of the middle teeth pair reduces and that of both sides increases. After analysis the reason is determined: due to the combine influence of the increased teeth and the deformation of the gear ring, the tip of the internal gear contacts sharply the root of the external gear in the meshing-in direction; the tip of the external gear contacts sharply the root of the internal gear in the meshing-out direction. The phenomenon in which the gear contact stress at both sides is increased significantly can be called acute angle effect, which will be more obvious when the meshing tooth number increases.

\section{Stress analysis of the five-teeth difference and the one-tooth difference}

Next, a comparative analysis of five-teeth difference and one-tooth difference is carry on,two cases about one-tooth difference are:Case 3: $z_{1}=30$ and $z_{2}=35$; Case 4: $z_{1}=100 、 z_{2}=105$. The distribution diagram of the root tensile stress of the external gear of Case 1 and Case 3, and that of Case 2 and Case 4 can be seen in Figure 6.

Compare the five-teeth difference and the one-tooth difference, when the teeth number is the same their stress distribution status is basically identical with relatively small difference can be found.

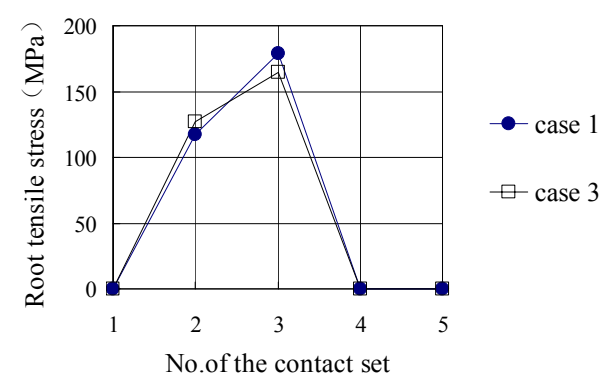

(a) Case 1 and Case 3

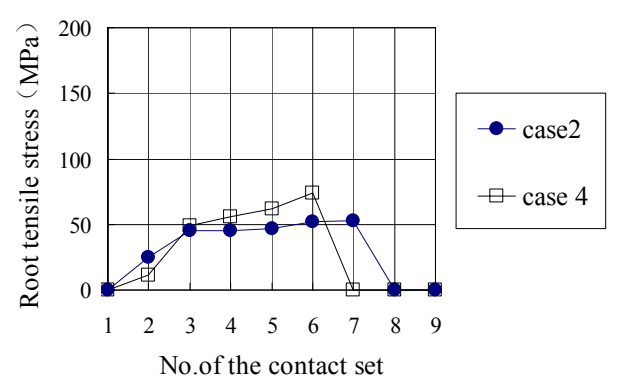

(b) Case 2 and Case 4

Figure 6 Distribution diagram of the root tensile stress

\section{Analysis of the teeth number of the multi-teeth meshing}

The meshed teeth number will increase when the load increases, while due to the joint restraint of the gear tooth clearance and the acute angle effect, it will never increase without limit, and the meshed teeth number has its maximum value. The maximum value of the one-tooth difference and five-teeth difference can be determined through the stress analysis and the data of stub gear can be seen in table 3 . The tooth number is small, the difference between the meshing teeth number of the 
one-tooth difference and five-teeth difference is small. With the increasing of the tooth number, the meshing teeth number of the five-teeth difference will reduce.

Table 3 Maximum of the meshing teeth number

\begin{tabular}{ccccccccccc}
\hline $\begin{array}{c}\text { Tooth number of the } \\
\text { external gear }\end{array}$ & 30 & 40 & 50 & 60 & 70 & 80 & 90 & 100 & 150 & 200 \\
\hline One-tooth difference & 2 & 2 & 3 & 4 & 4 & 4 & 5 & 6 & 10 & 15 \\
Five-teeth difference & 2 & 2 & 3 & 3 & 4 & 4 & 4 & 5 & 8 & 12 \\
\hline
\end{tabular}

\section{Conclusion}

Carry out the finite element analysis for the multi-teeth meshing phenomenon of involute internal gear pairs with small tooth number difference and disclose the characteristic of the tensile stress and the contact stress.

Discover the acute angle effect of the involute internal gear pairs with small tooth number difference; due to the constraint of the gear tooth gap and the acute angle effect, the tooth number of the multi-teeth meshing has a maximum value and provide the maximum value data of with small tooth number difference for stub gear.

\section{Acknowledgement}

In this paper, the research was sponsored by the Nature Science Foundation of Zhejiang Province (Project No. LY13E050022).

\section{References}

[1] X.N. Feng.Advanced Materials Research .Vol. 631-632 (2013), p.971

[2] X.L. Shu. and Q.X. Xia. Journal Of Machine Design .Vol. 19 (2002), p. 35

[3] S.T.Li.Mechanism and Machine Theory. Vol.42(2007):p.88

[4] S.T.Li. Mechanism and Machine Theory. Vol.43(2008):p.1065

[5] H.B.LI and K.Huang. Journal Of Liaoning Institute of Technology(Natural Science Edition) . Vol. 28 (2008), p. 250

[6]C.C.Ying, C.Zhang and Y.M.Song, etc. Journal Of Machine Design, Vol. 21 (2004), p. 12

[7]J.Fan, X.J. Meng and Y.Q. Cai. Journal Of Mechanical Transmission. Vol. 30 (2006), p. 73 